This is an electronic reprint of the original article. This reprint may differ from the original in pagination and typographic detail.

Author(s): Rahikainen, Ahti; Virmavirta, Mikko; Ranta, Matti A.

Title: Hill's Equation in the Arm Push of Shot Put

Year: $\quad 2016$

Version:

Please cite the original version:

Rahikainen, A., Virmavirta, M., \& Ranta, M. A. (2016). Hill's Equation in the Arm Push of Shot Put. British Journal of Applied Science and Technology, 18(5), Article no.BJAST.30766. https://doi.org/10.9734/BJAST/2016/30766

All material supplied via JYX is protected by copyright and other intellectual property rights, and duplication or sale of all or part of any of the repository collections is not permitted, except that material may be duplicated by you for your research use or educational purposes in electronic or print form. You must obtain permission for any other use. Electronic or print copies may not be offered, whether for sale or otherwise to anyone who is not an authorised user. 


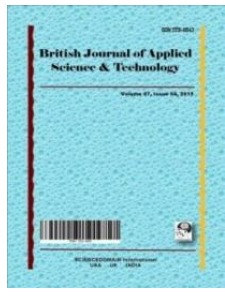

British Journal of Applied Science \& Technology

18(5): 1-12, 2016; Article no.BJAST.30766

ISSN: 2231-0843, NLM ID: 101664541

SCIENCEDOMAIN international

SCIENCEDOMAIN

www.sciencedomain.org

\title{
Hill's Equation in the Arm Push of Shot Put
}

\author{
Ahti Rahikainen ${ }^{1^{*}}$, Mikko Virmavirta ${ }^{1}$ and Matti A. Ranta ${ }^{2}$ \\ ${ }^{1}$ Department of Biology of Physical Activity, Neuromuscular Research Center, University of Jyväskylä, \\ Finland. \\ ${ }^{2}$ Aalto University, Finland. \\ Authors' contributions
}

This work was carried out in collaboration between the authors. Author AR designed the study, created the theory, performed the measurements and analysis and wrote the first draft of the manuscript. Author MV read, edited, and approved the final manuscript. Author MAR did the solution of Eq. (7) - Eq. (9) and approved the final manuscript.

Article Information

DOI: $10.9734 / B J A S T / 2016 / 30766$

Editor(s):

(1) Ya-mei Gao, College of Life Science and Technology, Heilongjiang Bayi Agariculture University, Daqing, Heilongjiang, China.

Reviewers:

(1) Adil Loya, PAF Karachi Institute of Economics and Technology, Pakistan.

(2) Danúbia da Cunha Sá-Caputo, Universidade do Estado do Rio de Janeiro, Rio de Janeiro, RJ, Brazil.

(3) Yüksel Savucu, Firat University, Elaziğ, Turkey.

Complete Peer review History: http://www.sciencedomain.org/review-history/17615

Original Research Article

Received $29^{\text {th }}$ November 2016

Accepted $19^{\text {th }}$ January 2017

Published $26^{\text {th }}$ January 2017

\section{ABSTRACT}

Aims: The purpose of this paper was to continue the previous study of arm rotation movement where A.V. Hill's force-velocity relationship was transformed into a constant maximum power model consisting of three different components of power.

Methodology: In the present study a new model of Hill's equation was applied for accelerated motions. This theoretically derived model of further development of Hill's force-velocity relationship was tested by fitting it into two arm push measurements of shot put experiments. The results of the further development of Hill's equation for accelerated motions were compared with the mechanics of the constant power model of the previous study.

Results: The analyses of the present study verified that this theoretically derived equation for accelerated motions was in agreement with the measured data of shot put experiments. The fittings succeeded and they coincided with the velocity curves of the measured shot put experiments and the constant power model of the previous study.

Conclusion: In the present study the progress of movement was concluded to be as follows: 1) the 
state of low speed, maximal acceleration which applies to the hypothesis of constant force, 2) the state of high speed, maximal power which applies to the hypothesis of constant power, where the constant power model of previous study and the present development of Hill's equation for accelerated motion were acting. This is a new approach to Hill's equation.

Keywords: Muscle mechanics; muscle power; force-velocity relationship; Hill's equation; arm movement; arm push in shot put.

\section{INTRODUCTION}

British Nobel laureate A.V. Hill invented the famous model of muscle mechanics which describes the force-velocity relationship of skeletal muscle contraction. The equation of this model is $(F+a)(v+b)=b\left(F_{0}+a\right)$, where $F$ is maximum force in muscle contraction, $a$ is constant force and $b$ is constant velocity, $F_{0}$ is isometric force of muscle or the constant maximum force generated by muscle with zero velocity and $v$ is velocity $([1,2]$, Fig. 1$)$. This equation was based on the laboratory measurements in which the force $(F)$ of activated muscle was measured as the muscle was contracting at a constant speed in an isolated condition. In the equation the vectors of forces and velocities have the same direction and therefore Hill's equation can be presented in a scalar form. Other early experiments of forcevelocity relationship of skeletal muscle were done by e.g. Fenn and Marsh [3] and good reviews are also available (e.g. [4,5]).

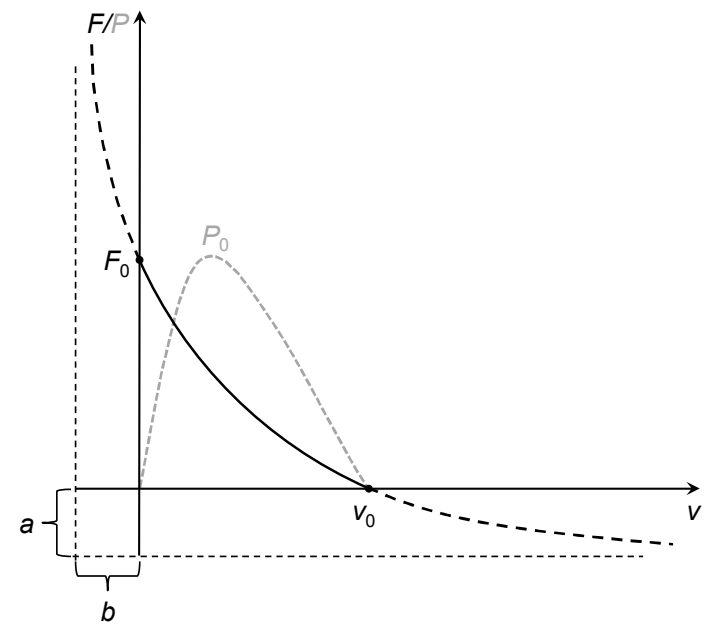

Fig. 1. Hill's force-velocity curve with the
corresponding power $P$

The arm rotation experiments of Rahikainen et al. [9] followed the theory, where movement was described to have four (4) different phases:
1) start of motion 2) movement proceeds at constant maximum rotational moment during the first part of the movement 3) movement proceeds at constant maximum muscular power during the second part of the movement 4) stopping of motion. For validation of these assumptions the equation was solved for angular velocity-time function:

$$
I \frac{d \dot{\varphi}}{d T}=\frac{P}{\dot{\varphi}}-C \dot{\varphi}
$$

This theoretically derived equation with constant maximum power (phase 3 above) was in good agreement with the experimentally measured results.

The study of Rahikainen and Virmavirta [6] continued the experiments of the previous study [7]) and further developed its theory of mechanics resulting in further solution of Hill's equation. The results were based on the assumption that in muscle mechanics there is a constant maximum power which the muscle is able to generate within a certain range of velocity. The principle of constant maximum power is also in Hill's equation and in this respect the two models can be considered the same. In the left side of Hill's equation the term $(F+a)(v+$ $b$ ) is muscles' total power including $F v$, which is the power of moving the external load. The right side of the equation, $b\left(F_{0}+a\right)$, includes only constants and thus the equation can be considered as a constant power model. However, the constant maximum power in the study of Rahikainen and Virmavirta [6] is a characteristic of whole muscle group instead of separate muscle fibers as in the Hill's equation. The model was based on the muscular system's ability to transfer chemical energy and, therefore, it is not necessary to know the contribution of the individual muscles involved. The constant power of Hill's equation presented by Rahikainen and Virmavirta [6] is not the power of Hill's original curve as it is usually considered in biomechanics, but it is the sum of three different power components. It was inferred that the constant 
power model of the study of this paper acts during high speed movements with no external load, where Hill's equation does not seem to fit the experimental points ([2], p. 32, Fig. 3.2) very well. As an explanation for this mismatch Hill mentioned that "sharp rise at the end of the curve in the region of very low tension was due to the presence of a limited number of fibers of high intrinsic speed and no such equation could fit the observed points below $P / P_{0}=0.05$ ". Because Hill's equation is also a constant power model, it is acting only in a certain state of motion, which is constant power movement at low speed of motion decelerated by counter force. Therefore it is not a model of motion which is suitable for every state of muscle motion.

Although Hill's force-velocity relationship has been an important part of muscular mechanics models, it has deficiencies which to a great extent restrict its application for the real muscular mechanics of human motion. Hill's equation is a constant power model and it has no term for the power of acceleration and therefore it cannot be applied within accelerated motions. Also at the point of maximum speed, where force is zero, Hill's equation does not seem to fit the experimental points well. The third reason for the deficiencies of the models based on Hill's equation is that they take no account of the effect of the elastic properties of muscle-tendon unit. The purpose of the present study was to further develop Hill's equation and to create a model, which could be applied to accelerated motions, and to test its function in arm push of the Olympic winner in shot put.

\section{METHODS}

\subsection{Hill's Equation in Accelerated Motion}

In order to find out the function of Hill's forcevelocity relationship in accelerated motion, equation of motion was derived from Hill's equation. In the present study Hill's equation is presented in a form

$$
(F+a)\left(v_{\mathrm{H}}+b\right)=\left(F_{0}+a\right) b
$$

where

$F$ is the muscular force in Hill's equation. The force $F$ must be constant during the whole muscle contraction. If it is not, the equation of motion of muscle contraction will be much more complex.
$v_{\mathrm{H}}$ is constant velocity in Hill's equation, and during the muscle contraction the muscular force $F$ corresponds to the velocity $v_{\mathrm{H}}$ in Hill's equation.

The results of Hill's experiments could be transformed into hyperbola equation describing force-velocity dependence of the movement. The left side of Hill's equation represents the maximum total power consumed into muscle contraction, and the right side of Hill's equation indicates that this maximum total power is constant. In the following this maximum total power is divided into three power components. Hill's equation, the motion with maximum constant power is the second state of motion. The first state of motion is with the maximum constant force, and in that state of motion acceleration is constant. Fig. 2 represents a further development of Hill's force-velocity relationship. Hill's equation, $(F+a)\left(v_{\mathrm{H}}+b\right)=$ constant, implies that the area of the rectangle $(F$ $+a)\left(v_{\mathrm{H}}+b\right)$ is constant. The total power of the muscle is comprised of three different components represented by rectangles $A, B$ and C. The area of rectangle $A=F v_{H}$ represents the power needed from muscle against an external load (see the power curve in Fig. 1). If there is no external load, this power is consumed by acceleration. The area of rectangle $B=(F+a) b$ represents the power of muscle's internal loss of energy. This power creates a counter force against an external load. As the velocity is zero, this power $B$ is highest and, therefore, it is not related to external movement. When velocity increases, this power decreases rapidly initially, then slowly at higher velocities. The area of rectangle $\mathrm{C}=v_{\mathrm{H}}$ a represents the power of friction due to the motion of the muscle - load system. Because power is force multiplied by velocity, the force of friction is $a$. This is not force directly proportional to velocity, generally known as liquid friction (which is the friction used in the present study in paragraph 2.3), but constant force of friction which is known as glide friction. Now we can see that there are three different states of motion: 1) at the beginning of motion characterized by a state of low speed constant maximal acceleration, then 2) as the motion continues a state of high speed, constant maximal power, which applies to motion of Eq. (21) and to Hill's equation. The maximum power is due to the fact that the transfer of energy within the muscle system must have a maximum rate and, therefore, muscle's power generation must also have a certain maximum rate. 


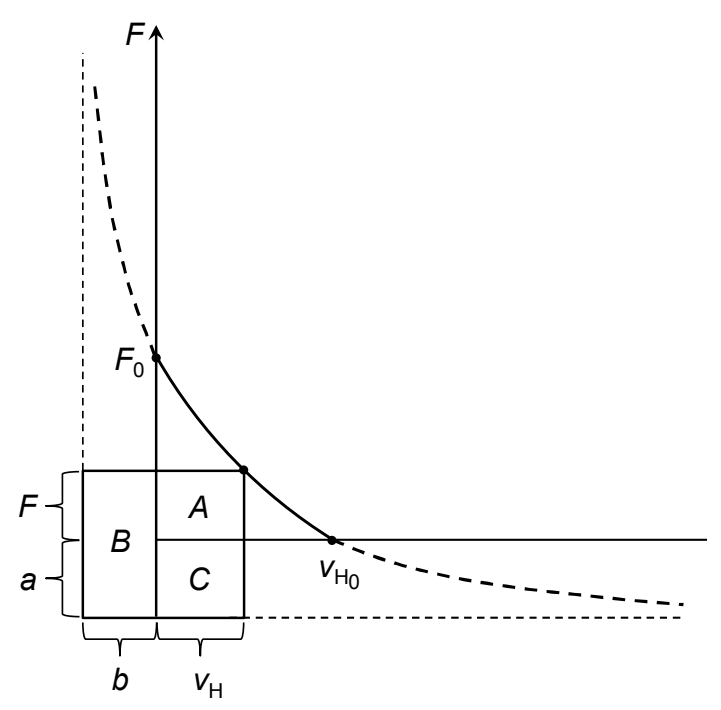

Fig. 2. Hill's force-velocity relationship presented with asymptotes (broken lines) and three rectangles of power. In traditional presentation of hyperbola $a$ and $b$ are negative, but here they refer to the positive constant terms of Hill' equation

Application of Hill's equation into human movement is problematic. Hill's force-velocity relationship has no power term for acceleration, and therefore it is not valid in accelerated motions. Hill's force - velocity relationship was measured with a measuring device in which the muscle force is measured at constant velocity. Its applications must also be constant velocity movements.

Herein theoretical experiment is performed: A mass $m$ is accelerated by a muscle contraction. The force generated by the muscle is $F$ and its counter force is $-F$. In the beginning velocity is zero, and the movement is at a state of high acceleration. As the movement continues, velocity $v$ increases and acceleration decreases, and if the movement continues sufficient long distance at some point the movement can be regarded as constant. Then there is force $F$ corresponding to velocity $v_{H}$ as it is in Hill's force - velocity relationship. The total power of Hill's equation can be divided into three separate power components (Fig. 2): the power of the work done against counter force $F v_{\mathrm{H}}$, the power of friction $a v_{H}$ and the power consumed within generation of muscle force $(F+a) b$. Because the muscle force $F$ is constant and $a$ and $b$ are also constants, the power $(F+a) b$ is also constant. The total power at the phase of constant velocity is the sum of the three rectangles $A, B$ and $C$ (Fig. 2) which is

$$
F v_{\mathrm{H}}+a v_{\mathrm{H}}+(F+a) b=(F+a)\left(v_{\mathrm{H}}+b\right)=\left(F_{0}+a\right) b
$$

At the phase of acceleration the power consumption into acceleration is

$$
P_{\mathrm{acc}}=m \frac{d v}{d t} v
$$

where $v$ is general velocity in movement containing also accelerated phase of motion.

Because at the phase of acceleration the velocity $v$ is less than the constant velocity $v_{\mathrm{H}}$, the power of the work done against counter force $F V$ and the power of friction av are less than that at the velocity $v_{\mathrm{H}}$. The difference of these powers is equal to the power into acceleration. We obtain the equation of motion

$$
\begin{aligned}
& m \frac{d v}{d t} v=F v_{\mathrm{H}}-F v+a v_{\mathrm{H}}-a v+ \\
& (F+a) b-(F+a) b=F\left(v_{\mathrm{H}}-v\right)+a\left(v_{\mathrm{H}}-v\right)
\end{aligned}
$$

Solution

$$
\begin{aligned}
& \frac{d v}{d t} v=\frac{F+a}{m}\left(v_{\mathrm{H}}-v\right) \\
& \frac{d v}{d t}=\frac{F+a}{m}\left(\frac{1-v / v_{\mathrm{H}}}{v / v_{\mathrm{H}}}\right) \\
& \left(\frac{v / v_{\mathrm{H}}-1+1}{1-v / v_{\mathrm{H}}}\right) d v=\frac{F+a}{m} d t \\
& \left(-1+\frac{1}{1-v / v_{\mathrm{H}}}\right) d v=\frac{F+a}{m} d t \\
& -\int d v-v_{\mathrm{H}} \int_{0}^{v}-\frac{1}{v_{\mathrm{H}}} \ln \left(\frac{1}{1-v / v_{\mathrm{H}}}\right) d v=\frac{F+a}{m} \int^{t} d t \\
& 0 \\
& -v-v_{\mathrm{H}}\left[\ln \left(1-v / v_{\mathrm{H}}\right)-\ln (1)\right]=\frac{F+a}{m} t+C
\end{aligned}
$$




$$
\begin{aligned}
& \text { constant } C=0 \\
& \ln (1)=0 \\
& t=-\frac{m}{F+a}\left[v+v_{\mathrm{H}} \ln \left(1-v / v_{\mathrm{H}}\right)\right]
\end{aligned}
$$

This is the equation of motion as mass $m$ is accelerated by muscle contraction. Hill's velocity $v_{\mathrm{H}}$ corresponds to muscle force $F$ in Hill's equation. Hill's velocity is the velocity after the phase of acceleration as the motion can be regarded as constant velocity movement. Calculation of the values of Hill's velocity $v_{H}$ and muscular force $F$ (Eq. 1) are

$$
\begin{aligned}
& (F+a)\left(v_{\mathrm{H}}+b\right)=\left(F_{0}+a\right) b \\
& F\left(v_{\mathrm{H}}\right)=\frac{F_{0} b-a v_{\mathrm{H}}}{v_{\mathrm{H}}+b}
\end{aligned}
$$

Substituting $F=0$ into Hill's equation

$$
\begin{gathered}
a v_{\mathrm{H} 0}=F_{0} b \\
b=\frac{a v_{\mathrm{H} 0}}{F_{0}}
\end{gathered}
$$

\subsection{Numerical Calculations of Hill's Equation in Accelerated Motion}

Theoretical velocity functions of the mass lifted against gravity force by muscle contraction are determined by selecting constant values $F_{0}=1 \mathrm{~N}$ and $v_{\mathrm{H} 0}=1 \mathrm{~m} / \mathrm{s}$ (for convenience), and $a / F_{0}=$ 0.27 ([8], p. 194). Moving mass $m$ is equal to force divided by gravitational coefficient $m=F / g$.

First Hill's velocities are chosen for the curves of contraction equations which will be calculated $\left(v_{\mathrm{H}}=0.2 \mathrm{~m} / \mathrm{s}, 0.4 \mathrm{~m} / \mathrm{s}, 0,6 \mathrm{~m} / \mathrm{s}, 0.8 \mathrm{~m} / \mathrm{s}, 0.9 \mathrm{~m} / \mathrm{s}\right.$, Fig. 3). Then the values of constant force $a=$ $0.27 F_{0}$ and constant velocity $b$ using Eq. (14) are chosen $(a=0.27, b=0.27)$. After that the corresponding values of force $F$ using Eq. (12) are calculated $(F=0.460 \mathrm{~N}, 0.242 \mathrm{~N}, 0.124 \mathrm{~N}$, $0.051 \mathrm{~N}, 0.023 \mathrm{~N}$, Fig. 3). Finally corresponding

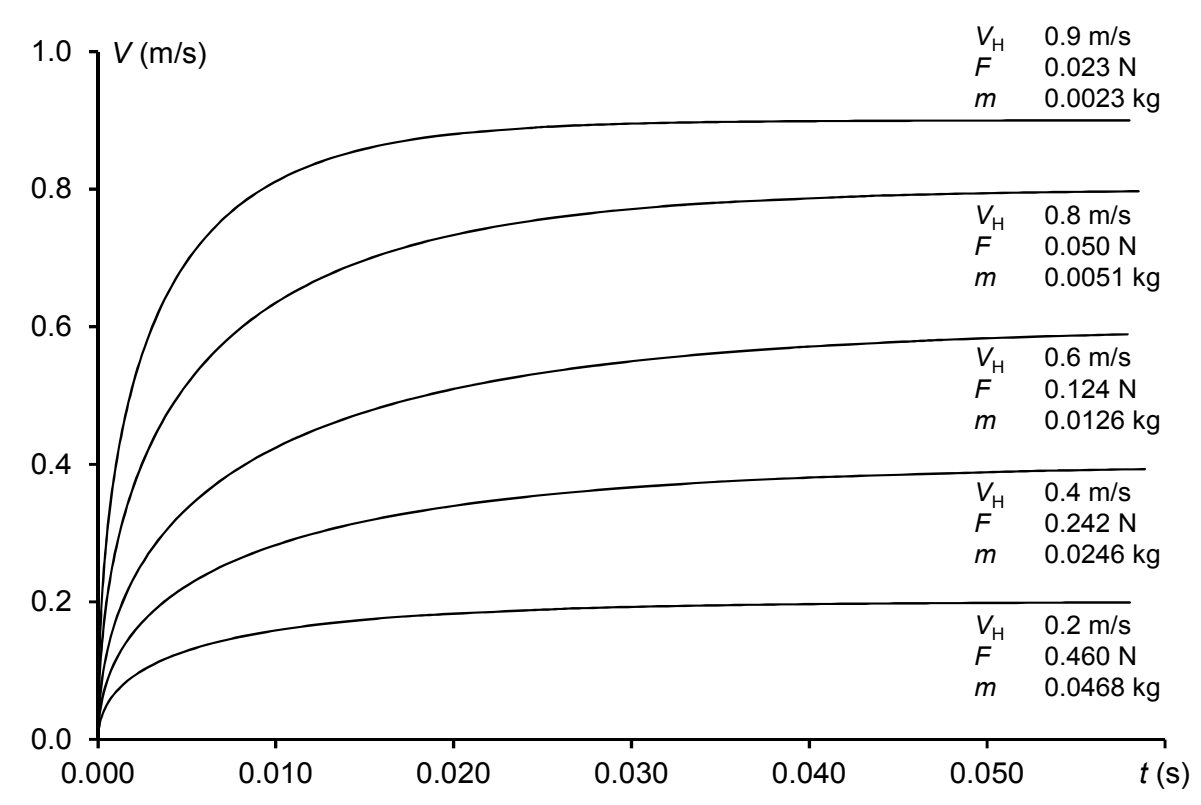

Fig. 3. Velocity curves of moving mass accelerated in muscle contraction resisted by counter force which is equal to the force of gravitation. Hill's velocity $v_{H}$ is the limit velocity that the velocity of the moving mass approaches. Hill's velocity $v_{H}$ corresponds to the velocity in the Hill's force velocity relationship and the force $F$ corresponds to the force of Hill's force velocity relationship 
values of force $F$ and Hill's velocity $v H$ are substituted into equation of muscle contraction (Eq. 11), and the velocity curves of mass accelerated in muscle contraction resisted by constant counter force $F$ are obtained, (Fig. 3).

\subsection{Constant Power - Liquid Friction Model of Muscle Contraction}

The model used in the present study is constructed according to Newton's II law, which was first used in linear motion of arm push in shot put [9] and then applied to rotational motion by Rahikainen et al. [7] and Rahikainen and Virmavirta [6]. The theory of arm movement is as follows: At the beginning of the movement, velocity is naturally zero and it takes some time to generate force. At that phase of motion, passive elements of muscle-tendon unit have influence on the motion, but after reaching the full state of tension, they have no further dynamic effect. After that it can be assumed that a maximum muscle force takes action and at that phase of motion constant value glide friction acts. Because the muscle system is able to transfer only a certain quantity of chemical energy during the time of contraction, there must be a constant maximum power, which the muscle is able to generate within a certain range of velocity. As the velocity increases the motion reaches the point where the maximum power takes action and acting force is less than the maximum force. This way power remains constant as the velocity increases and the force decreases. At high velocity phase of motion, liquid friction, directly proportional to velocity, acts. The constant value glide friction decreases as forces at the joint decrease and it becomes indifferent. The model of arm movement during constant power phase in shot put study was constructed as follows: accelerating force is mass multiplied by acceleration which equals muscle force minus the force generated by inner friction of muscle. The effect of gravitational force is added afterwards.

$$
m \frac{d V}{d T}=\frac{P}{V}-C V
$$

where

The weight of the shot $7.27 \mathrm{~kg}$ and the weight of the arm approximately $3.5 \mathrm{~kg}$, or total weight $10.8 \mathrm{~kg}$ (Table 1).

$\begin{array}{ll}\text { Mass of shot and arm } & m \\ \text { Velocity of shot } & V \\ \text { Power generated by arm } & P \\ \text { Time of arm push } & T \\ \text { Pushing force } & P / V \\ \text { Internal friction in arm } & C V\end{array}$

Internal friction of muscle is liquid friction inside muscle, which is directly proportional to velocity. The same liquid friction was also used in the study of Rahikainen et al. [7] which was initially adopted from Alonso and Finn [10].

Table 1. Body segment masses [11] and estimated moving mass of the shot putter (140 $\mathrm{kg})$ in the present study

\begin{tabular}{llll}
\hline & $\begin{array}{l}\text { \% of } \\
\text { total } \\
\text { mass }\end{array}$ & $\begin{array}{l}\text { mass } \\
\mathbf{( k g )}\end{array}$ & $\begin{array}{l}\text { moving } \\
\text { mass } \\
\mathbf{( k g )}\end{array}$ \\
\hline 1 trunk & 34.70 & 48.6 & \\
2 upper arm L & 2.65 & 3.7 & \\
3 forearm L & 1.82 & 2.5 & \\
4 hand L & 0.50 & 0.7 & \\
5 upper arm R & 2.65 & 3.7 & $1 / 4=0.925$ \\
6 forearm R & 1.82 & 2.5 & $3 / 4=1.875$ \\
7 hand R & 0.50 & 0.7 & 0.7 \\
8 shot & & 7.3 & 7.3 \\
9 head & 6.72 & 9.4 & \\
\hline
\end{tabular}

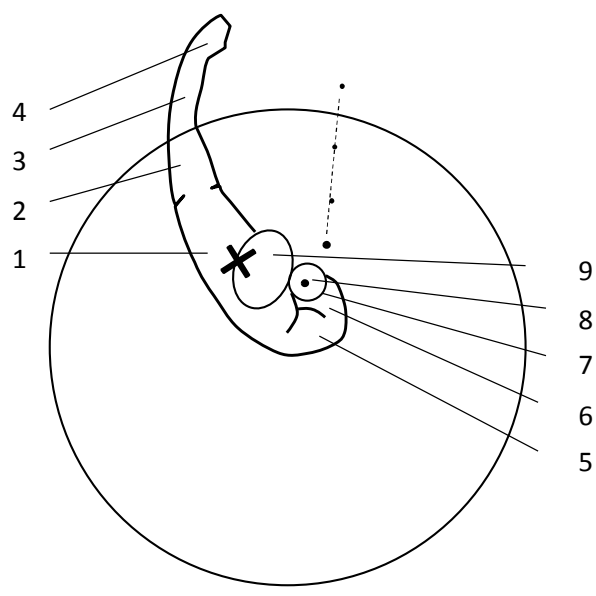


Solution of velocity in Eq. (15)

$$
\begin{aligned}
& m \frac{V}{P-C V^{2}} d V=d T \\
& -\frac{m}{2 C} \int_{0}^{V}-2 C V \frac{1}{P-C V^{2}} d V=\int_{0}^{T} d T \\
& \ln \left(P-C V^{2}\right)-\ln (P)=-\frac{2 C}{m} T \\
& \ln \left(\frac{P-C V^{2}}{P}\right)=-\frac{2 C}{m} T \\
& 1-\frac{C}{P} V^{2}=e^{-\frac{2 C}{m} T} \\
& V=\sqrt{\frac{P}{C}\left(1-e^{-\frac{2 C}{m} T}\right)}
\end{aligned}
$$

\subsection{Effect of Gravitational Force on the Movement in Shot Put}

The force which is induced by gravity was omitted from the motion model. The power generated by this gravity force is $P_{\mathrm{gr}}=$ $m g \cdot \sin \left(41^{\circ}\right) \cdot V=69.5 \mathrm{~N} \cdot V$, where $m g$ is gravitational force of moving mass (Fig. 4 ), $V$ is velocity of arm movement. In Fig. 6 , velocity ( $V$ in
Eq. 21) coincides the measured velocity curve between 4 and $6 \mathrm{~m} / \mathrm{s}$ and the best fit for power $(4750 \mathrm{~W}$, Fig. 6) is in the middle of these velocities, at $5 \mathrm{~m} / \mathrm{s}$. As the force of gravity is relatively small, the power induced by gravity was calculated in this study as a constant factor. It is included in the power $P$ as follows; 1 )

$$
\begin{aligned}
& P_{0}=P_{\mathrm{acc}}+P_{\mathrm{fr}}+P_{\mathrm{gr}} \\
& P=P_{0}-P_{\mathrm{gr}}=P_{\mathrm{acc}}+P_{\mathrm{fr}}
\end{aligned}
$$

$P$ is power in Eq. (21), $P_{0}$ is muscle power, acc is acceleration, $\mathrm{fr}$ is friction, $\mathrm{gr}$ is gravity, force of gravity is $F$. At the point $B$ in Fig. 5 velocity is 4 $\mathrm{m} / \mathrm{s}$ and the real power can be calculated as follows; 2)

$P_{\text {real }}=P+(5-4) \mathrm{m} / \mathrm{s} \cdot F=4750 \mathrm{~W}+69.6 \mathrm{~W}=$ 4819.6 W

The real velocity can be solved from the power ratio of Eq. (21); 3)

$$
\begin{aligned}
& V_{\text {real }} / V=\sqrt{4819.6 / 4750}=1.0073 \\
& V_{\text {real }}=4 \cdot 1.0073=4.029 \mathrm{~m} / \mathrm{s}
\end{aligned}
$$

which is within the accuracy of this study $4 \mathrm{~m} / \mathrm{s}$

In constant acceleration phase of movement

$$
F_{0}=F_{\mathrm{acc}}+F_{\mathrm{fr}}+F
$$

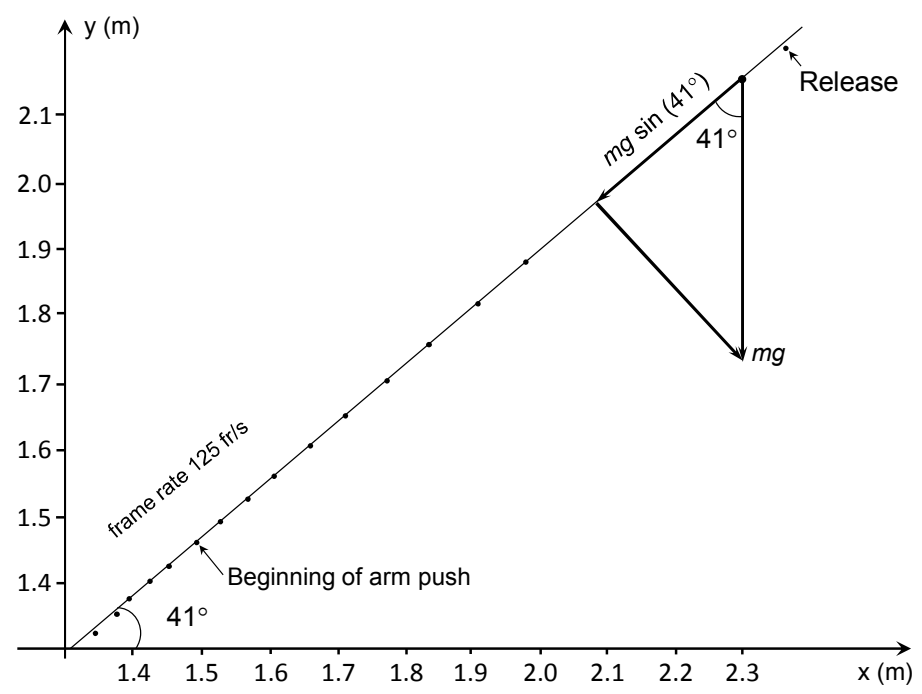

Fig. 4. Sideview of shot's path during the arm push (distance of the put $19.47 \mathrm{~m}$ ) 


\section{RESULTS}

\subsection{Analysis of $19.47 \mathrm{~m}$ Put Using Eq. (21)}

If the time of arm push is known, it is possible to determine the speed of shot during the arm push using speed curves from Rahikainen and Luhtanen [9], (Figs. 5 and 6). Thereby, the part corresponding to the time of arm push is separated from the end of the speed curve (e.g. Fig. 5). In the path of the shot (Fig. 6) it can be seen that in section $A$ - $B$ the arm push continues to generate speed with the maximal pushing force and the inclination of the speed curve is almost constant. This is because the maximal generation of speed is limited by the shot putter's maximal arm-pushing force. As the arm push continues, in section B - C - D, the pushing force accelerating the shot decreases and the inclination of the speed curve decreases as well. There are three different factors that cause the decrease in acceleration. First: as the speed of the shot increases, the rate of increase is not limited by a maximal pushing force, but by a maximal propulsive power, in which case force is power divided by velocity. Second: The internal friction of the pushing arm, which can be considered to be directly proportional to the velocity, decreases the velocity of the shot. Third: as the shot putter in the rotational motion turns sideways in respect to the direction of the arm push, the pushing force of the arm decreases and disappears and the arm just follows the shot without accelerating it. In Fig. 6 the broken line describes the effect of the first and second factor mentioned above. In section B - C, the measured speed curve and the broken line coincides. In this phase of the arm push, the two above-mentioned factors are the principal factors influencing the speed of the shot. In section $\mathrm{C}-$ $D$, the measured speed curve travels under the broken line. In this phase of the arm push, the shot putter turns so much sideways in respect to the direction of the arm push that the acceleration of the shot decreases further. If the shot putter would not turn (or rotate) during the arm push, the measured speed curve would combine with the broken line in section C - E. By fitting Eq. (21) into the measured speed curve in Fig. 6 values of internal friction and power are obtained $\mathrm{C}=64.8 \mathrm{~kg} / \mathrm{s}$ and $\mathrm{P}=4750 \mathrm{~W}$.

\subsection{Analysis of Arm Push in Shot Put Using Hill's Equation}

In Hill's equation the velocity of muscle contraction $v_{H}$ is measured, as the force $-F$ is resisting the motion. The muscle force is then $F$. In the beginning of movement the velocity of muscle contraction is zero, then the muscle force accelerates the motion, and the velocity increases. At some point it reaches maximum value, and at this constant speed phase of movement, velocity $v_{\mathrm{H}}$ in Hill's equation corresponds to the muscle force $F$. Theoretically the time of motion for the constant maximum velocity $v_{\mathrm{H}}$ is indefinite, but if the counter force $-F$ is strong enough, the movement decelerates and the constant maximum phase really exists in

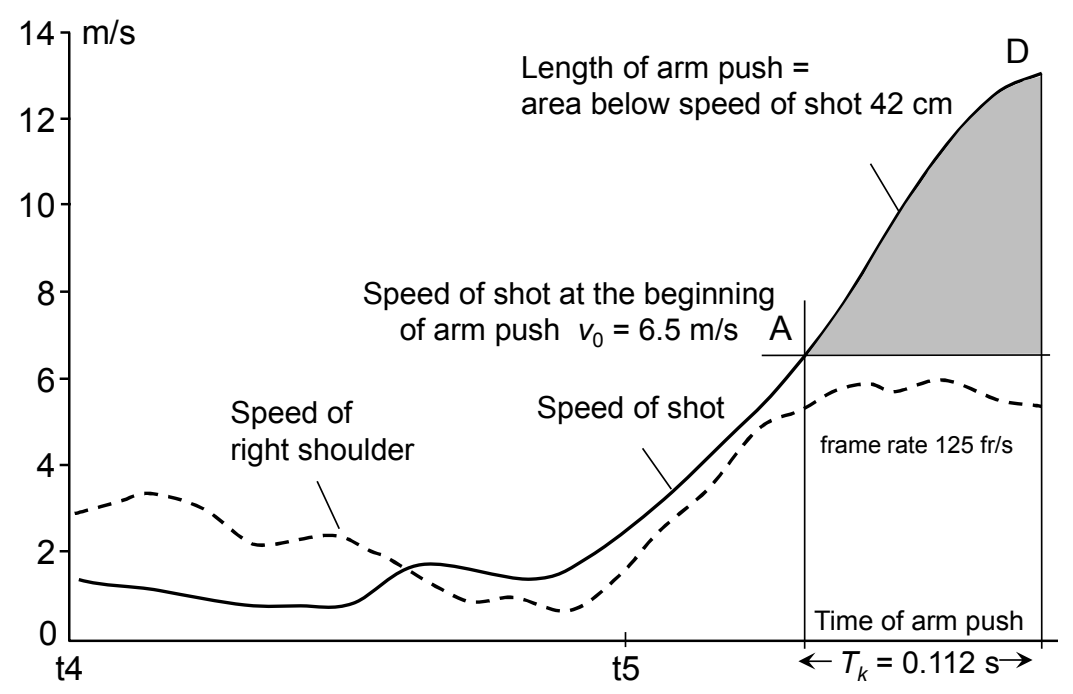

Fig. 5. The measured speed of the shot and the length of arm push (shaded area A-D) in 19.47 m put 


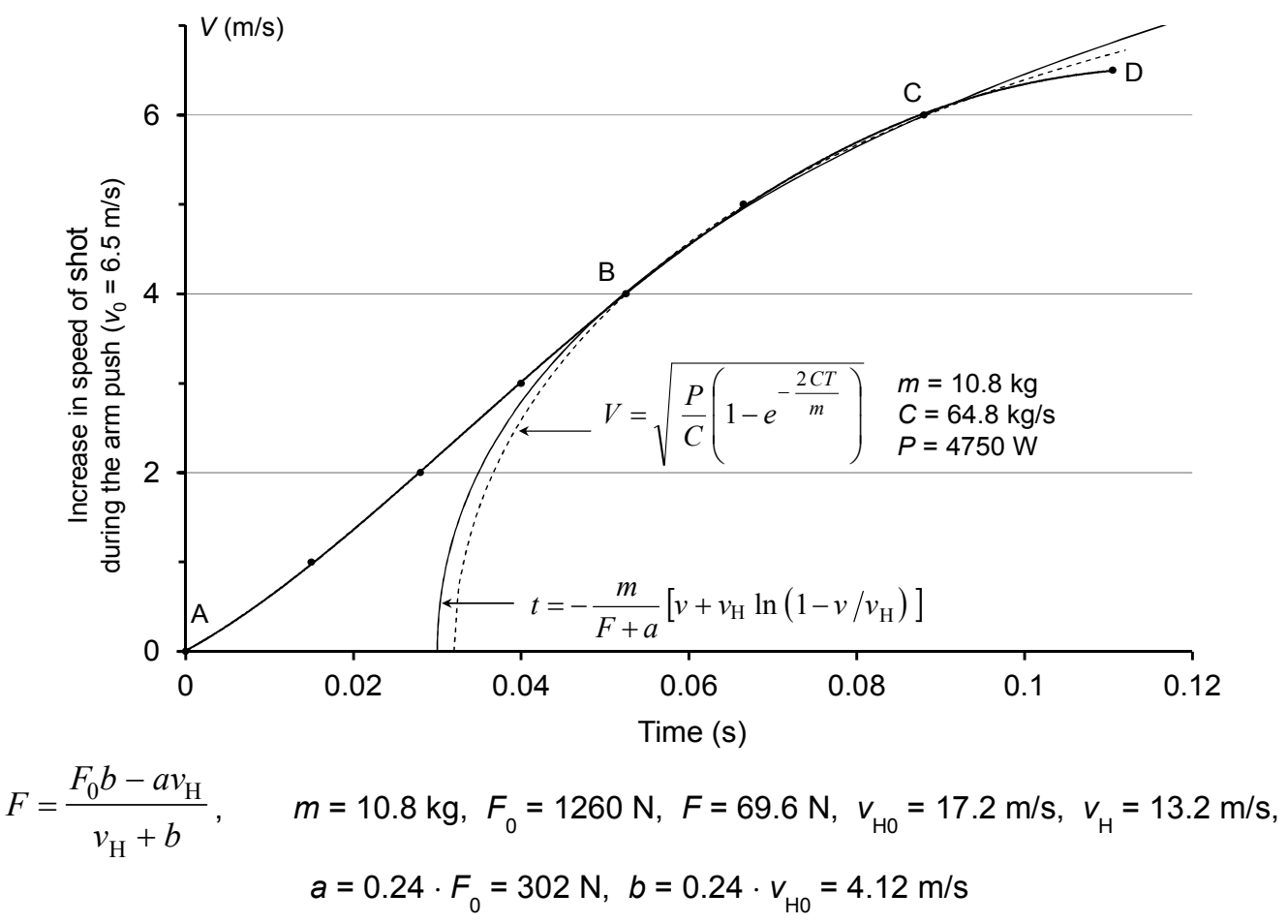

Fig. 6. The measured speed of the $19.47 \mathrm{~m}$ shot put (curve $A-B-C-D$ ) and the theoretical speed curves, dashed line from Eq. (21) and solid line from Eq. (11). The zero time ( $T=0)$ for theoretical curves is at 0.032 and $0.030 \mathrm{~s}$, respectively

muscle mechanics. All the velocities $v$ from zero to maximum velocity correspond to muscle forces greater than $F$ (muscle force $\cdot$ velocity $=$ constant power) and therefore in this study the maximum velocity corresponding $F$ is marked as Hill's velocity $v_{\mathrm{H}}$.

In arm push of shot put the corresponding progress of velocity does not reach the velocity value $v_{H}$ because the range of movement is too short for that. In that movement all the velocity values are calculated from Eq. (11).

$$
t=-\frac{m}{F+a}\left[v+v_{\mathrm{H}} \ln \left(1-v / v_{\mathrm{H}}\right)\right]
$$

\subsection{Determining the Constants in Eq. (11)}

The moving mass $m$ is presented in Table 1 . Gravitational force of the moving mass is $m g=$ $10.8 \cdot 9.82=106 \mathrm{~N}$ and the force resisting the acceleration of the shot is $-F=-\mathrm{mg} \cdot \sin \left(41^{\circ}\right)=$ $-69.6 \mathrm{~N}$, and the muscle force of Hill's equation is $F=69.6 \mathrm{~N}$.

The maximum muscle force $F_{0}$ can be determined by two different ways. Shot putter's maximum bench press with two hands has been measured $260 \mathrm{~kg}$ and thus the estimated result for one hand is $130 \mathrm{~kg}$. The maximum muscle force is then $F_{01}=130 \mathrm{~kg} \cdot 9.82 \mathrm{~m} / \mathrm{s} 2=1280 \mathrm{~N}$. The other way to determine the maximum muscle force $F_{02}$ is to use Eq. (21) which yields the value of power $4750 \mathrm{~W}$ (Fig. 6). At the velocity of $4 \mathrm{~m} / \mathrm{s}$ this power gives the force 4750 $\mathrm{W} / 4 \mathrm{~m} / \mathrm{s}$, and by adding the force of gravity of shot and hand the maximum muscle force is obtained $F_{02}=4750 \mathrm{~W} / 4+69.6 \mathrm{~N}=1260 \mathrm{~N}$.

Constant $a$ in Eq. (11) is the constant value glide friction, and it can be determined in the phase of constant acceleration between $A$ and $B$ (V between $\sim 1.5-3.5 \mathrm{~m} / \mathrm{s}$, Fig. 6 ) as follows: Force of friction $a$ is equal to the maximum muscle force $F_{0}$ subtracted the gravitational force resisting acceleration $F$ and the force of acceleration $F_{\text {acc }}$. The force of acceleration $F_{\text {acc }}$ is equal to moving mass $m$ multiplied by acceleration. The acceleration can be determined from the phase of constant acceleration by measuring the corresponding changes of velocity and time, $\mathrm{dV} / \mathrm{d} T=82 \mathrm{~m} / \mathrm{s} 2$, and the force of acceleration is 


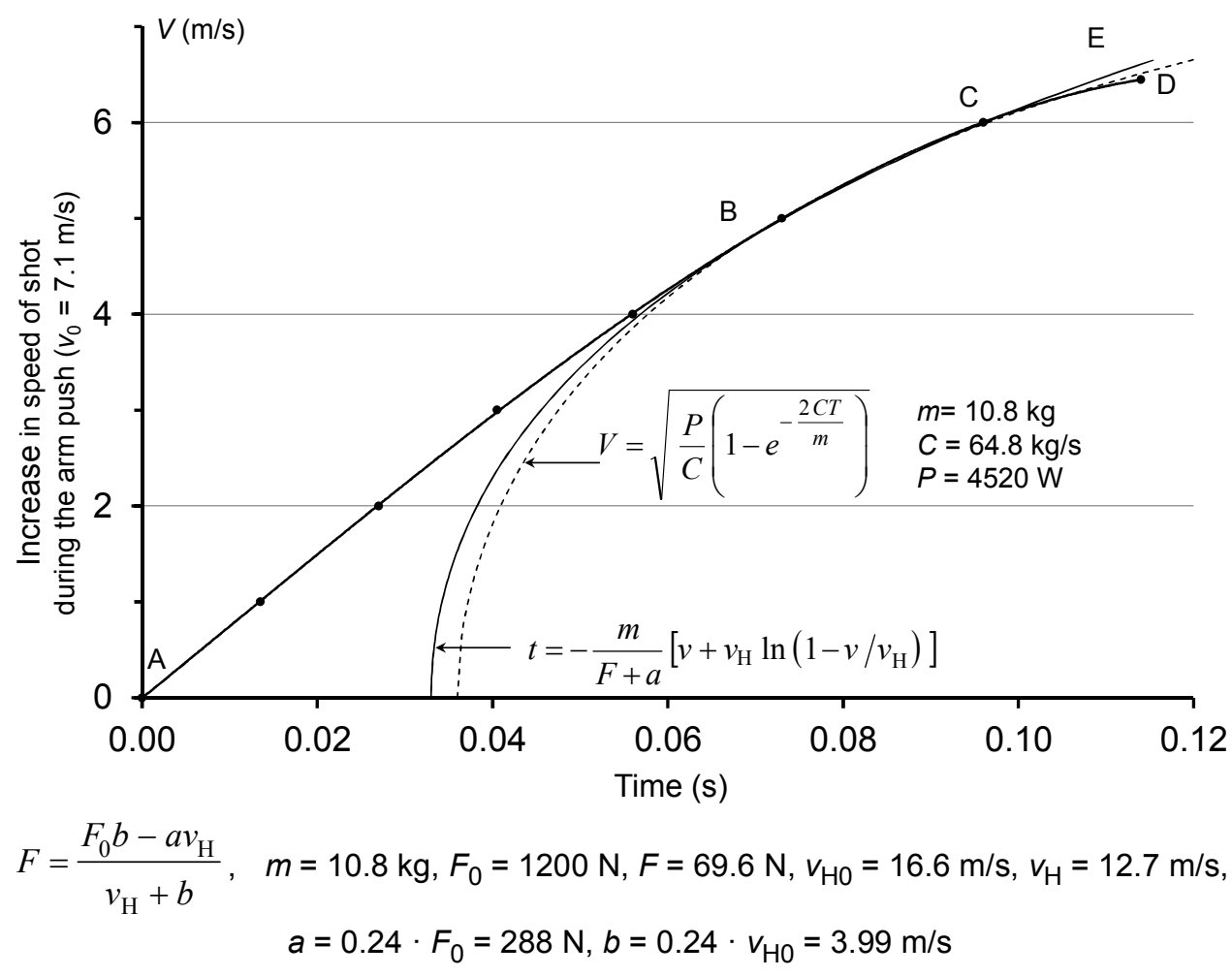

Fig. 7. The measured speed of the $20.90 \mathrm{~m}$ shot put (curve $A-B-C-D$ ) and the theoretical speed curves, dashed line from Eq. (21) and solid line from Eq. (11). The zero time (T=0) for theoretical curves is at 0.032 and $0.030 \mathrm{~s}$, respectively

$F_{\text {acc }}=10.8 \mathrm{~kg} \cdot 82 \mathrm{~m} / \mathrm{s} 2=888 \mathrm{~N}$. The force of friction (using $F_{02}$ ) is $a=1260 \mathrm{~N}-888 \mathrm{~N}-69.6$ $=302 \mathrm{~N}$ and the coefficient of friction is $302 \mathrm{~N} /$ $1260 \mathrm{~N}=0.24$.

Hill's velocity $v_{H}$ can be determined by iteration. Iteration can be done (for instance) so that Eq. (11) is calculated with proper value of $v_{H}$ through the intersection point of the measured velocity curve and the line of the velocity $4 \mathrm{~m} / \mathrm{s}$ (point B). The value of $v_{H}$ is then found by iteration so that Eq. (11) matches the measured velocity curve at the velocity of $6 \mathrm{~m} / \mathrm{s}$ (point $\mathrm{C}$ ). Increase of the velocity value $v_{\mathrm{H}}$ results in increase of inclination of the iterated velocity curve. Constant $b$ is calculated from Hill's equation.

\subsection{Analysis of $20.90 \mathrm{~m}$ Put}

Another shot put performance (20.90 m, [9]) was analyzed in order to be able to compare the two puts and to learn more about the characteristics of the arm push. Another analysis was also needed to confirm the validity of the equation of motion. Measured speed curve of this put (dots) is presented in Fig. 7. The speed which is calculated with Eq. (21) coincides with the speed of further development of Hill's equation Eq. (11) in section $B-C$ (Fig. 7). The propulsive power of the arm push is approximately $P=4520 \mathrm{~W}$. The arm push in Fig. 6 has a greater pushing force $1260 \mathrm{~N}$ than in Fig. $71200 \mathrm{~N}$, but at the end of the push the decrease in acceleration in Fig. 6 is so great that the total velocities generated during both arm pushes are almost equally high. The reason for the large decrease in acceleration is probably due to muscle's mechanics, maybe a pressure decrease in muscles as the turning of the body is getting larger. In the optimal arm push, this large acceleration decrease must be eliminated.

\section{CONCLUSIONS}

Rahikainen et al. [7] showed that in the first part of the arm rotation movement acceleration was constant and during the second part of movement equation of constant power (Eq. 21) fitted the measured velocity curve. The following 
study (Rahikainen and Virmavirta [6]) continued the arm rotation experiments and a new approach to Hill's equation was presented. The shot put experiments of the present study have the similar progress of movement with the previous ones, and the above mentioned constant acceleration and constant power phases have been proved to be true as well. The correct functioning of Eq. (21) is also proven as the two forces $F_{01}=1280 \mathrm{~N}$ and $F_{02}=1260 \mathrm{~N}$ (see paragraph 3.3 ) are very close to each other.

In Figs. 6 and 7 the measured velocity curve has a phase of constant acceleration between velocity values $\sim 1.5-3.5 \mathrm{~m} / \mathrm{s}$ and it can be inferred that within this range of velocity constant maximum muscle force is produced presuming that the force of friction is constant value glide friction. The constant friction a in the phase of constant acceleration and in the phase of constant power in Eq. (11) is assumed to be the same and mechanics in the equation seems to function properly with this assumption. In Maclntosh and Holash [8] the values of friction coefficient $a / P_{0}$ for human elbow flexors are given, $0.45,0.4$ and 0.39 , in which $P_{0}$ is maximum moment for values 0.4 and 0.45 and maximum force for value 0.39 and a corresponds to the force of friction. Values of friction coefficient $a / P_{0}$ 0.2-0.3 are also used. Proper functioning of Hill's equation implies the action of counter force $F$ and if the counter force is weak, velocity increases, and the friction coefficient $a / P_{0}$ may be bigger $0.6-0.7$.

The original purpose of this study was to find out how well the models of Eq. (21) and the further development of Hill's equation, Eq. (11), match the measured velocity in the arm pushes of two shot put performances. The fittings of these two constant power equations succeeded and they did function very much the same manner. Both of power equations fitted the measured velocity curve between velocity values $4-6 \mathrm{~m} / \mathrm{s}$ and thus the constant power model proved to be true within this range of velocity. However, these two models of constant power (Eq. 11 and Eq. 21) are different and they differ at higher velocities significantly. The highest velocity value of the further development of Hill's equation (Eq. 11) in Fig. 6 is $v_{H}=13.2 \mathrm{~m} / \mathrm{s}$ and the highest velocity of Eq. (21), after the correction presented in paragraph 2.4 , is $V_{\text {real }}=8.345 \mathrm{~m} / \mathrm{s}$.

Within the present study two arm pushes of shot put were analyzed with success and the constant power model of the further development of Hill's equation in maximum velocity was verified. It was also verified that in the phase of constant acceleration three different constant forces are acting: the force of acceleration, the force of friction and the force of gravity and added together they represent the maximum muscle force. The range of correspondence between the measured and theoretical velocities of the shot put experiments was long enough to confirm the existence of constant power models. Kinetic friction was assumed to be directly proportional to velocity at the beginning of the movement. It is possible that kinetic friction at small velocities is constant and at high velocities is directly proportional to velocity. This leads to a constant torque accelerating the movement at the beginning of movement. It is also possible that the constant acceleration phase of movement is rather a matter of human ability to learn effective modes of motion than a direct cause of natural laws. It may be that human nervous system controls the rotational moment accelerating the arm movement.

The present application of Hill's equation in accelerated motion could be worth to apply in the accelerated rotational movement as well. The analysis of additional subjects with different performance level would also help to better understand the function of Hill's equation in accelerated movement.

\section{COMPETING INTERESTS}

Authors have declared that no competing interests exist.

\section{REFERENCES}

1. Hill $A \bigvee$. The heat of shortening and the dynamic constants of muscle. Proc. Royal Soc. London. 1938;126(B):136-195.

2. Hill AV. First and last experiments in muscle mechanics. Cambridge University Press, Cambridge; 1970.

3. Fenn WO, Marsh BS. Muscular force at different speeds of shortening. Journal of Physiology. 1935;85(3):277-297.

4. Herzog W. Force-velocity relation. In: Nigg BM, Herzog W, (Eds.) Biomechanics of the Musculo-Skeletal System 3rd ed. John Wiley \& Sons Ltd. Chichester. England. 2006;202-209.

5. Seow CY. Hill's equation of muscle performance and its hidden insight on 
molecular mechanisms. Journal of General Physiology. 2013;142(6):561-573.

6. Rahikainen A, Virmavirta M. Constant power model in arm rotation - A new approach to Hill's equation. World Journal of Mechanics. 2014;4:157-169.

7. Rahikainen A, Avela J, Virmavirta M. Modeling the force-velocity relationship in arm movement. World Journal of Mechanics. 2012;2:90-97.

8. Maclntosh BR, Holash RJ. Power output and force velocity properties of muscle. In: Nigg BM, Maclntosh BR, Mester J, Eds. Biomechanics and Biology of Movement
Human Kinetics. Human Kinetics. Champaign. IL. 2000;193-210.

9. Rahikainen A, Luhtanen P. A study of the effect of body rotation on the arm push in shot put. Russian Journal of Biomechanics. 2004;8(2):78-93.

10. Alonso M, Finn EJ. Damped oscillations. In: Alonso M, Finn EJ. Fundamental University Physics I, Second Edition. Addison-Wesley Publishing Company. 1980;352:504.

11. Hochmuth G. Biomechanik sportlicher Bewegungen. Sportverlag Berlin. 1981; 117.

(c) 2016 Rahikainen et al.; This is an Open Access article distributed under the terms of the Creative Commons Attribution License (http://creativecommons.org/licenses/by/4.0), which permits unrestricted use, distribution, and reproduction in any medium, provided the original work is properly cited.

Peer-review history:

The peer review history for this paper can be accessed here: http://sciencedomain.org/review-history/17615 